\title{
Diacronie
}

Studi di Storia Contemporanea

$\mathrm{N}^{\circ} 28,4 \mid 2016$

La voce del silenzio

\section{La conspiración turco-comunista: espías, contrabandistas e instructores en el Rif}

Daniel Macías Fernández

\section{(2) OpenEdition}

\section{Journals}

Edición electrónica

URL: https://journals.openedition.org/diacronie/4699

DOI: $10.4000 /$ diacronie.4699

ISSN: 2038-0925

Editor

Association culturelle Diacronie

Referencia electrónica

Daniel Macías Fernández, «La conspiración turco-comunista: espías, contrabandistas e instructores en el Rif», Diacronie [En línea], № 28, 4 | 2016, documento 3, Publicado el 29 diciembre 2016,

consultado el 21 septiembre 2021. URL: http://journals.openedition.org/diacronie/4699 ; DOI: https:// doi.org/10.4000/diacronie.4699 


\section{Diacronie}

N. 28 | 4|2016 La voce del silenzio: intelligence, spionaggio e conflitto nel XX secolo

\section{3/}

\section{La conspiración turco-comunista: espías, contrabandistas e instructores en el Rif}

\section{Daniel MACÍAS FERNANDEZ*}

Las Campañas de Marruecos (1909-1927) y, especialmente, la denominada Guerra del Rif (1921-1927), que se insertaba en el ciclo bélico anteriormente citado, fue la ardua e ingrata misión a la que se destinó a la parte más operativa y ambiciosa del ejército español de comienzos del siglo XX. Las trabas y los problemas que tuvieron para "pacificar" la región que les correspondía por los acuerdos internacionales, acabaron llevando a la inteligencia militar a pensar en intromisiones extranjeras. Espías, informadores y una red de contraespionaje fueron temas protagonistas de una abundante documentación generada por la administración colonial y las legaciones diplomáticas españolas por las cuatro esquinas del mundo. Fueron muchos los militares que alertaron de complots extranjeros en el Protectorado y del trasiego de pertrechos bélicos por la zona, los cuales iban destinados a facciones rebeldes de nativos.

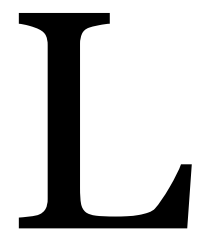

as Campañas de Marruecos fueron una serie de operaciones militares de mayor o menor envergadura en las que se vio inmerso el Ejército español entre 1909 y 1927. El escenario de tales conflagraciones bélicas fue el área septentrional del Sultanato de Marruecos, aquel que correspondía "proteger" a la potencia ibérica dentro de lo acordado en la Conferencia de Algeciras (1906).

Las casi dos décadas de irregulares contiendas castrenses fueron ilustrativas de la timorata política "imperial” española. La penetración colonial española se caracterizó por la intermitencia de la actividad militar en el Marruecos bajo su protección, mayor o menor, en función de la situación internacional, de los cambios gubernamentales en 
Madrid, de la disponibilidad de recursos para el sector de ejército español que servía en África, así como de las actuaciones llevadas a cabo por Francia en su Protectorado y también de las propias dinámicas provocadas por los indígenas de la zona adjudicada a España en el co-Protectorado, es decir, la región conocida generalmente como Rif.

Las dificultades que tuvo el Ejército colonial para "pacificar" la zona que le correspondía se debían, en opinión de muchos de los militares que sirvieron en aquel escenario, a las reacciones adversas de la mayor parte de la opinión pública nacional a su "misión" (poca moral de los soldados destinados a la colonia), el comportamiento de los políticos (errático, vacilante y poco comprometido), los a todas luces insuficientes recursos precisos para acometer la tarea encomendada... Éstas eran las principales trabas que debieron sortear los oficiales castrenses -en un número bastante elevado -, que operaban en territorio africano, y cuya génesis estaba basada en cuestiones muy concretas: el contrabando, el espionaje y los enemigos de la patria que eran los causantes de las debacles militares o, al menos, los catalizadores de las mismas. Los detractores del "destino" imperial español eran considerados en bloque como enemigos de la Patria, ya fuesen extranjeros o nacionales, estos últimos abducidos por ideologías foráneas.

Desde el punto de vista de la política exterior, la situación de rivalidad colonial entre España y Francia en Marruecos había facilitado la proliferación de contrabandistas y espías que vendían armas e información a los respectivos enemigos de los países colonizadores. La porosidad de las fronteras de la Zona española y la Zona francesa complicó, aún más, las operaciones militares. La permeabilidad de los términos administrativos se complicaba, además, con una abrupta orografía, la inexistencia de infraestructuras viales, un clima desértico y de alta montaña en amplias áreas del territorio rifeño, cursos de agua intermitentes y en general escasos (aridez general y escasez de fuentes de agua potables), la ausencia de una autoridad estatal centralizadora, la dispersión de la población, la falta de planos cartográficos, la belicosidad de los nativos (guerra de guerrillas) experimentados en los frecuentes enfrentamientos entre las propias tribus, así como de estas mismas contra el Sultán o contra las potencias coloniales...

\section{Agentes extranjeros en el Rif}

Los agentes extranjeros infiltrados en el Protectorado español de Marruecos tuvieron una gran presencia en los documentos generados por el ejército colonial. La 
experiencia de los curtidos militares españoles en tal teatro de operaciones norteafricano incluyó la sospecha permanente de la presencia de espías enemigos.

Los intereses geopolíticos de las distintas potencias internacionales en las diversas coyunturas históricas que van desde 1909 a 1927 y la atracción que generaban las supuestas riquezas del subsuelo rifeño, hicieron que el Protectorado español fuese un territorio con un considerable número de agentes extranjeros insertos en el escenario norteafricano; tales individuos mostraban una amplia panoplia de intereses. Después de la derrota española en Annual (1921) hubo un incremento del número de individuos interesados en hacer negocios con un nuevo agente internacional: la República del Rif ${ }^{1}$. Un informe reservado de 1926 contenía el nombre y los datos más destacados de un buen número de agentes relacionados con los rifeños y que estaban interesados en conseguir las concesiones mineras de esa zona central del Marruecos español:

Gordon Cunning: [...] decía llevaba poderes del Rey y el Gobierno Inglés [...] Capitán Munday [...] Spencer Price [...] Madame Arnall: Era viuda de un tal Yuus Arnall especulador de minas [...] formando parte de la Compañía Británica del Rif, justamente con Sid Abd-el-Krim el Hach Ali y otro llamado Sivera. Estos estaban en relación con una compañía Inglesa de minas².

La zona internacional de Tánger, "puerta por donde se recibieron armas y dinero con que fomentar la rebelión", fue un motivo de preocupación constante para los Altos Comisarios por las prácticas de contrabando y de espionaje3. En ese mismo sentido, la previamente aludida porosidad de las fronteras francesas, producto de la rivalidad franco-española hasta mediados de los años veinte, debilitaba las posibilidades de control real del territorio por parte del ejército colonial de España. Fueron muchos los testimonios que nos certifican las malas prácticas francesas hacia los intereses españoles en la región y, aunque en menor medida, los británicos también fueron puestos bajo sospecha por sus ambiciones sobre Tánger y sus intereses gibraltareños.

Los españoles desarrollaron una red de contraespionaje para intentar tener controlados a los agentes extranjeros en el Protectorado bajo su soberanía; ésta emitía

\footnotetext{
${ }^{1}$ La República del Rif fue el régimen que instauró Abd el Krim el Jatabi tras hacer retroceder a las fuerzas españolas a la denominada Línea Estella (1921). El caudillo rifeño creó un Estado embrionario basado en el nacionalismo bereber que llegó hacer retroceder a las fuerzas francesas cuando atacó la zona bajo soberanía francesa en 1924. Abd el Krim se acabó rindiendo al ejército galo en 1926, aunque la rebelión rifeña prosiguió hasta la pacificación total en 1927.

2 En el Informe sobre el interrogatorio a que ha sido sometido el noruego de 40 años Walter Hungens, europeo al servicio de los rifeños, en Archivo General Militar de Madrid, Fondo África, Ministerio de la Guerra, Est. 3, Cuerpo 1, Tab. 9, Leg. 474, Carpeta 4.

3 FRANCO BAHAMONDE, Franco, Papeles de la guerra de Marruecos, Madrid, Fundación Nacional Francisco Franco, 1986, p. 255.
} 
informes altamente clasificados a los respectivos Comandantes Generales. Se informaba de los movimientos de sujetos sospechosos de trabajar para potencias foráneas o se seguía y sondeaba a sus supuestos informadores. Sirva de ejemplo la carta de don Ricardo Ruiz al general Aizpuru del 23 de noviembre de 1923, en la que además de informaciones de contraespionaje contenía una plantilla pormenorizada de los gastos surgidos en el transcurso de su misión, entre los que figuraba el pago a una prostituta, medio usado para obtener información:

\begin{abstract}
...instrumento indirecto, aunque costoso, en esta empresa [de espionaje]. [...] la dama en cuestión tratada como tal por nosotros, disimulando la natural repulsión que por su liviandad pueda merecernos, [...] nos permita estar al tanto de sus andanzas y si posible fuera hasta de sus designios y proyectos 4 .
\end{abstract}

El estallido de la Primera Guerra Mundial (1914) fue un punto de inflexión en la percepción de los servicios secretos extranjeros en el Protectorado español. Alemanes, turcos, franceses y británicos pugnaban por atraerse distintos grupos indígenas a sus respectivas causas y provocar el máximo daño posible a sus respectivos rivales e intereses. En ese periodo se establecieron una serie de redes de información y espionaje que sentaron las bases de la total desconfianza española ante potenciales agentes extranjeros. Esa percepción se intensificó merced a algunas consecuencias de la Gran Guerra (1914-1918) como la caída de la Rusia zarista (1917) y subsiguiente proclamación de la URSS (1922), el destino de los excedentes bélicos y la aparición de la Turquía de Mustafá Kemal Atatürk (1922).

El comunismo y la aparición del nacionalismo en el mundo musulmán fueron considerados por los militares coloniales españoles de ideologías corruptoras del orden mundial establecido. Ambas constituían un potencial peligro para los intereses de España en Marruecos, misión nacional que no había de ser truncada por los nuevos enemigos de la patria: comunistas y "nacionalistas panislámicos". Aunque los planteamientos ideológico-políticos de los anticolonialistas del mundo musulmán (turcos, árabes, bereberes, iraníes...) y de los comunistas tenían muy poco que ver entre sí, la inteligencia militar española tendió a unir tales corrientes de pensamiento en una misma categoría, a saber: la de máximos enemigos de España. Por ello, las conspiraciones islamista-bolcheviques fueron el "fantasma" que sobrevolaba los intereses del estamento colonialista castrense español. Esto fue especialmente

\footnotetext{
4 En Archivo General de la Administración, AGA, África, 81/10598.
} 
destacado durante la denominada Guerra del Rif (1921-1927), el periodo más cruento de las Campañas de Marruecos.

\section{El comunismo}

El peligro del comunista era percibido en dos vertientes. La primera se refería a la existencia de esa misma corriente de pensamiento dentro de la metrópoli y en el contexto europeo. Ésta era la causante del anticolonialismo y el antimilitarismo que se consideraba como un foco de infección de la sociedad española y europea en general con sus ideas subversivas, de entre las cuales la lucha de clases fue de las más denostadas por el estamento castrense. La segunda variante del peligro comunista venía de la Unión Soviética y estaría compuesta por agentes bolcheviques, la propaganda revolucionaria, así como las armas y recursos con los que se pretendería subvertir el orden mundial establecido.

La importancia de la supuesta ayuda bolchevique a los rebeldes marroquíes marcó el estereotipo del enemigo comunista en la cosmovisión de los militares colonialistas. El general Franco se refirió al apoyo de "sectores comunistas" a Abd el Krim para justificar la resistencia de éste, al mismo tiempo que aseveró la existencia de "agentes comunistas" sobre el terreno apoyando la insurrección 5 . El general Gómez-Jordana fue más preciso al referirse a lo que consideró uno de los máximos aliados de la República del Rif:

Los comunistas, muy interesados en fomentar la rebeldía del Rif, con vista a descomponer interiormente a Francia y España, pues paralelamente a su labor cerca de Abd-el-Krim llevaban su propaganda a las mismas filas del ejército, tratando de desmoralizarlo, y a las masas populares que se revolviesen contra la guerra ${ }^{6}$.

El comunismo internacional se valía de todos los medios posibles para la obstaculización de las acciones españolas en el Protectorado. Sus agentes se infiltraban en el ejército e introducían en él ideas subversivas. El Tercio de Extranjeros, por su carácter internacional, era una unidad bajo estrecha vigilancia para prevenir la existencia de agentes comunistas en el mismo. Millán Astray intentó dejar bien claro

5 FRANCO BAHAMONDE, Francisco, Papeles de la guerra..., pp. 233, 257.

6 GÓMEZ-JORDANA SOUZA, Francisco, La tramoya de nuestra actuación en Marruecos, Madrid, Editorial Nacional, 1976, p. 97. 
cuál era el espíritu de la Legión cuando escribió que las ideas políticas "quedan en la puerta de la Legión" aunque no parece que siempre fuese así, atendiendo a ciertas noticias del periodo de la Guerra del Rif7. En un documento reservado del periodo de la Guerra del Rif se citaba un "complot que preparaban tres legionarios Comunistas alemanes, los cuales resultaron muertos cuando intentaban escapar de la escolta que los custodiaba conduciéndoles a Melilla"8.

Los informes cifrados que describían el tipo de prensa a la que tenían acceso los soldados de servicio en Marruecos fueron comunes en las primeras décadas del siglo XX. La recepción de periódicos de carácter obrerista (El Socialista por ejemplo), eran castigados severamente y se intentó evitar toda posible influencia de tales publicaciones en el ejército de África. Más gravedad tenía la posesión de rotativos, pasquines o panfletos de naturaleza comunista, a los que se veía como órganos de influencia extranjera sobre las tropas españolas. Un telegrama cifrado del 20 de agosto de 1924 ilustra el tipo de sanciones con los infractores: «Artillero Pedro Antonio Bauza, [...], recibe periódicos comunistas [...] y hace propaganda activa. He dispuesto su prisión y formación causa»9.

El cuidado que se ponía en proteger al ejército de África de toda "contaminación" comunista se relacionaba con la importancia de la institución militar como auténtico cortafuegos de la revolución. La naturaleza extra-peninsular del ejército colonial española hacía pensar en que era posible mantenerlo aislado de las corrientes revolucionarias comunistas. En cualquier caso, la institución armada tenía la función de guardián del orden existente y no se podía permitir la existencia de núcleos subversivos dentro de la misma. En un informe especial de carácter muy confidencial de diciembre de 1925 se decía:

\footnotetext{
PARA EVITAR LA POSIBILIDAD DE QUE SE PROPAGUE EL MAL ES PRECISO CONOCERLO y conocer la táctica del enemigo. A esto obedece esta INFORMACIÓN que ha de llegar a todos aquellos que, hallándose al frente de núcleos de Ejército deben velar por mantenerlo íntegro y acorazarle contra las estrategias de Moscú10.
}

\footnotetext{
7 MILLÁN ASTRAY, José, La Legión, Madrid, Editorial Palomeque, 1922, p. 143.

${ }^{8}$ En Archivo General Militar de Madrid, Fondo África, Ministerio de la Guerra, Est. 2, Cuerpo 6, Tab. 8, Leg. 406, Carpeta 1.

9 "Telegrama del Capitán General al General encargado Despacho", del 20 de agosto de 1924, en Archivo General Militar de Madrid, Fondo África, Ministerio de la Guerra, No Clasificado (rollo 1227).

10 Documento Confidencial, Información especial de diciembre de 1925 con el título "El Comunismo y el Ejército", en Archivo General Militar de Madrid, Fondo África, Ministerio de la Guerra, Est. 3, Cuerpo 1, Tab. 1, Leg. 440, Carpeta 2.
} 
El texto precedente señalaba a Moscú como centro difusor de "células" revolucionarias destinadas a minar el país desde dentro. Las intenciones comunistas eran sembrar discordia en la "familia" castrense, una de las peores acciones que se podía concebir por un militar, que tenía en el compañerismo y, sobre todo, en el orden y la disciplina, sus máximos valores.

La variedad de estrategias comunistas para socavar el poder español a través del debilitamiento de su ejército fue lo que llevó a pensar a los militares coloniales en la conspiración Islam-Comunismo, algo que respondía al siguiente razonamiento: la misión imperial de España en Marruecos era fundamental para el fortalecimiento de la patria y toda interrupción en la misma significaría un obstáculo para los intereses nacionales, por lo que los revolucionarios de Moscú propiciarían una alianza con los musulmanes norteafricanos. Los bolcheviques eran, siguiendo la lógica anterior, capaces de cualquier alianza con tal de destruir el país; el desgaste del ejército colonial, que era el más operativo y potente, debilitaría irremisiblemente a los garantes del orden y permitiría la agitación revolucionaria en la metrópoli. En un documento clasificado del 22 de octubre de 1927 se manejaron las claves enunciadas:

[...] bueno es hacer este estudio y advertir el peligro [...], que se traduce en creer que MARRUECos, con todo eso que tiene y que hemos citado [religión musulmana], dispone de un escudo contra este grave mal.

¿Qué cómo puede suceder esto? Pues muy sencillo; dándole a la propaganda comunista toda la flexibilidad necesaria para que sea de fácil importación $\mathrm{y}$ adaptación en cualquier país y para cualquier habitante ${ }^{11}$.

La adaptación del comunismo a las esencias musulmanas estuvo marcada por la excitación del sentimiento nacionalista árabe o bereber. Los informes españoles señalaban la insistencia de la propaganda bolchevique en la transmutación de la lucha de clases al escenario colonial: españoles como propietarios de los medios de producción y "moros" como proletarios. El 31 de mayo de 1927 se dirigió un informe a la Presidencia del Consejo de Ministros en el que se manifestaba: «Esos instintos seculares con los que simpatiza el Islamismo [...], son amplia, intensa y tenazmente aprovechados por el comunismo imperante en Rusia ${ }^{12}$.

\footnotetext{
${ }^{11}$ Estudio sobre "El comunismo en Argelia", que fue enviado al Alto Comisario y las Oficinas Consulares de España en Tánger, Argel, Oran, Sidi-Bel-Abbes, Túnez, Rabat, Casablanca, Fez, Mogador, Safi y Mazagan, desde la Oficina Mixta Hispano-Francesa (Málaga) el 22 de octubre de 1927. En Archivo General de la Administración, AGA, África, 81/10341.

${ }^{12}$ Informe reservado del 31 de mayo de 1927 dirigido a la Presidencia del Consejo de Ministros, en Archivo General de la Administración, AGA, África, 81/10341.
} 
En un informe del 31 de mayo de 1927 se manifestaban las actuaciones del comunismo ruso: «[...] ejerce su principal acción [en el Protectorado] en lo que se refiere a la propaganda moral entre los indígenas, [aunque] no descuida la menor oportunidad para introducir material de guerra como natural consecuencia de sus predicaciones»13. El peligro de penetración de agentes y de propaganda revolucionaria en el contexto colonial marroquí era, según los documentos vistos, constante. Falta concretar hasta qué punto el comunismo pudo dotar al "Islamismo" de apoyo material. La constatación de la existencia de esta ayuda, especialmente relevante en lo referente a pertrechos militares, es muy difícil de demostrar por la propia naturaleza de la misma: contrabando y redes de espionaje. A pesar de ello, existen diversos documentos clasificados españoles que aludían a envíos de material bélico desde repúblicas de Europa del Este. En un informe del 26 de mayo de 1927, el embajador español en Varsovia enviaba el siguiente telegrama al general Gómez-Jordana: «...uno de los documentos comunistas [intervenidos] habla de "salida de armas para el RIF y los nacionalistas catalanes de ODESA" ${ }^{14}$. Aunque puedan parecer informaciones un tanto inverosímiles, lo cierto es que existieron redes de agentes españoles en distintos países de Europa central y oriental para controlar los envíos de armas y pertrechos bélicos. Ello indica la percepción que se tenía del peligro comunista en relación a los movimientos insurgentes en países musulmanes. En un telegrama del 11 de julio de 1928 se recomendaba la clausura de la red española de informadores de Hamburgo y Amberes, puesto que el peligro sedicioso rifeño era mínimo tras la "pacificación” del territorio marroquí en el año anterior:

Juzgo posible ya, que, en vista de que el tráfico directo o indirecto de armas y municiones con MARRUECos, parece haber cesado totalmente, (...), se deje de abonar fija y mensualmente, el sueldo que los agentes que tenemos en HAMBURGO y AMBERES vienen cobrando ${ }^{15}$.

\footnotetext{
${ }_{13}$ Informe reservado del 31 de mayo de 1927 dirigido a la Presidencia del Consejo de Ministros, en Archivo General de la Administración, AGA, África, 81/10341.

${ }^{14}$ Información proporcionada por el embajador español en Varsovia (Polonia). En telegrama del 26 de mayo de 1927 de la Comisión Mixta Hispano-Francesa (Málaga) al general GómezJordana, en Archivo General de la Administración, AGA, África, 81/10341.

15 Telegrama reservado número 1979 , enviado el 11 de julio de 1928 por el Tte. Coronel de la Oficina Mixta Hispano-Francesa (Málaga) al Director General de Marruecos y Colonias. En Archivo General de la Administración, AGA, África, 81/10341.
} 
El telegrama clasificado muestra esa certeza: que el ejército colonial español tenía ante la «conspiración mundial de los soviets» ${ }^{16}$. Las redes de información españolas en el extranjero tenían por finalidad neutralizar los envíos de armas y agentes soviéticos al territorio norteafricano bajo supervisión española. Redes que, tras la alianza hispanofrancesa de 1924 destinada a acabar con la República del Rif, se completaron con intercambios de información y el trabajo conjunto contra el peligro comunista y "panislámico" a través de la Oficina Mixta Hispano-Francesa.

En general, se deben destacar las informaciones vinculadas a personas de nacionalidad turca, ciudadanos que tuvieron especial relevancia en los documentos hispano-franceses confidenciales. Los complots internacionales contra el orden y la estabilidad en Marruecos solían vincular a turcos y comunistas en su subversión del septentrión africano. El eje Ankara-Moscú fue motivo de constante preocupación para las potencias coloniales. En su manual para oficiales coloniales, el auditor Del Nido y Torres se expresó en los siguientes términos sobre la Revolución Soviética y las reformas de Mustafá Kemal en Turquía: «En este Pacto [de Angora] y en esas doctrinas sovietistas [sic] se apoya la actual agitación del islamismo, [...] [y] el problema marroquí»17. La república de Atatürk formó tándem con la Rusia soviética para encarnar el "eje del mal” de los militares coloniales franco-españoles.

Los comunistas no sólo se entrometían en el control de la colonia, también “contaminaban" con sus ideas a la metrópoli para minar el ánimo del pueblo español e, indirectamente, perjudicar la expansión de España en Marruecos. El marxismo era la encarnación de todo lo malo desde la cosmovisión de los colonialistas castrenses y la mayor parte de los problemas metropolitanos fueron cargados sobre los hombros de tan buen "chivo expiatorio": la oposición popular a las Campañas de Marruecos y a servir en tal escenario era, evidentemente, culpa de la influencia soviética. De esta forma se podía justificar la bondad del sujeto "pueblo español" en tanto que éste habría sido engañado por falsas ideas foráneas -comunistas- que lo habrían llevado a desviarse de la causa patriótica. El general Mola llegó a explicar que aquellos que propagaban mensajes "derrotista[s]" eran «no pocas veces agentes a sueldo de organizaciones extranjeras» ${ }^{18}$.

16 Telegrama reservado número 1979, enviado el 11 de julio de 1928 por el Tte. Coronel de la Oficina Mixta Hispano-Francesa (Málaga) al Director General de Marruecos y Colonias. En Archivo General de la Administración, AGA, África, 81/10341.

${ }^{17}$ Auditor de División DEL NIDO Y TORRES, Manuel, Marruecos, apuntes para el oficial de intervención y de tropas coloniales, Tetuán, Editorial Hispano Africana, 1925, p. 286.

${ }_{18}$ MOLA VIDAL, Emilio, Obras completas, Santander, Aldus, 1940, p. 1155. 
La larga mano revolucionaria llegó, incluso, a amenazar la vida del rey Alfonso XIII; un informe fechado en 1917 decía: «Noticias de un comité constituido en Orán [...] Se teme acción revolucionaria y acaso atentado contra el Rey»19. Más comunes fueron las noticias que desarrollaban las intenciones comunistas referentes a la sociedad metropolitana con la intención de boicotear la acción en Marruecos.

Lo cierto es que los militares se percibían como los "guardianes de la patria" y percibieron en los comunistas la sombra de la injerencia extranjera - Moscú - que estaba maniobrando "para destruir España”. Esta supuesta intención soviética tenía su campo preferente de actuación en Marruecos, donde la dinámica bélica permitía la sangría de las fuerzas españolas.

\section{El movimiento "panislámico"}

El despertar "nacionalista panislámico" no fue percibido por los militares coloniales como un fenómeno autóctono - marroquí -, sino que era una consecuencia de hechos acaecidos en otros lugares del mundo y sujetos a intereses extranjeros. Ya hemos destacado la importancia que se otorgó al comunismo soviético en este sentido. Éste era el causante de la mayor parte de los desórdenes coloniales, al incentivar el nacionalismo/islamismo en áreas musulmanas, aunque hubo otro catalizador esporádico de la rebelión o del peligro de la misma: Alemania. La enemistad francogermana, antes, durante y después de la Gran Guerra, hizo que agentes alemanes espoleasen los sentimientos anti-coloniales marroquíes para perjudicar a Francia, yendo esto, al mismo tiempo, contra los intereses españoles. Otra variante de la intromisión alemana en Marruecos fue a través de agentes del comunismo internacional de origen germano pero, en este caso, la responsabilidad de tal hecho volvía a recaer en el marxismo. Un volumen propagandístico contra los intereses franceses, firmado por el coronel alemán Bode y editado en 1926, que circulaba entre soldados germano-parlantes del Tercio de Extranjeros español, sirve para ejemplificar lo dicho'20.

En cualquier caso, fue la Turquía de Kemal Atatürk el otro gran protagonista del despertar "panislámico" que tanto aterraba a los militares españoles. Antes de empezar a analizar dicho fenómeno, se debe destacar que el mando peninsular no tenía una idea

19 Documento manuscrito que parece ser una copia de un telegrama cifrado que estaba fechado en 1917, no consta remitente ni remite. Por la fecha, no podemos asegurar que la palabra "revolucionario" se refiera al comunismo aunque, en cualquier caso, tales actos fueron generalmente asociados a tal concepto.

${ }_{20}$ En Archivo General de la Administración, AGA, África, 81/10341. 
demasiado clara de conceptos tan diversos como nacionalismo, islamismo, panarabismo o panislamismo. La literatura militar del periodo y los documentos de archivo provenientes del ejército de España en África suelen meter en el mismo saco todos los esos términos, siendo entendidos como sinónimos o algo muy cercano. Lo importante era que, el conjunto de los mismos, suponían movimientos anti-coloniales y eso era ya lo verdaderamente destacable. En este sentido, el general Mola escribió: «[...] han aparecido [en Marruecos] focos de nacionalismo, o mejor dicho, de panislamismo, fomentados por agentes europeos y fanáticos e intelectuales indígenas ${ }^{21}$.

La denominada Guerra de Liberación de Turquía (1919-1923), acaecida tras la derrota del Imperio Otomano en la I Guerra Mundial, fue motivo de preocupación constante para la inteligencia española. Muchos fueron los que vieron vínculos entre el Movimiento Nacional Turco y la República del Rif. En un documento de 1926 procedente de la Escuela de Estado Mayor se señalaba como una da las causas de la rebeldía rifeña “...el panislamismo que se fomentó a raíz de los éxitos de Mustafá Kemal contra los griegos”22. El líder de la independencia turca -Atatürk- era un nacionalista partidario de una república laica y moderna según los cánones occidentales del periodo, un modelo que nada tenía que ver con los movimientos religiosos musulmanes. Aunque es comprensible una cierta confusión por la propia dinámica del proceso de conversión del Imperio Otomano en la República de Turquía, lo que suponía una evidente contradicción porque, por un lado se apreciaba el hecho de que el otrora potente imperio otomano tan temido en Occidente desde las postrimerías del siglo XV, se convirtiese en un estado de cuño occidental y totalmente identificado con los valores de la Europa de entonces (exceptuada la URSS) y, por otro, cómo ese nuevo estado surgido de uno de los procesos revolucionarios más interesantes del siglo XX, se hallaba en franca connivencia con Moscú y con pretensiones ciertas respecto a la "exportación” de esa revolución laica y occidentalista al resto de estados musulmanes, muchos de los cuales habían estado sometidos al imperio turco hasta 1918, siempre desde la perspectiva de un estado laico pero de religión mayoritariamente islámica aunque no perteneciente a la familia árabe ni étnica ni culturalmente. Esa circunstancia era la que desconcertaba a los políticos y jefes militares españoles.

Dentro de la Guerra de Independencia turca llegó a haber dos gobiernos, el del Sultán en Estambul y el de Kemal Atatürk en Ankara. Esta circunstancia fue la que generó, probablemente, una gran incertidumbre a los servicios de información

${ }^{21}$ MOLA VIDAL, Emilio, op. cit., p. 1111.

22 ALAMÁN, Eduardo, La guerra de Marruecos. El desembarco de Alhucemas y operaciones posteriores, s.l., s.n., 1926. Documento mecanografiado perteneciente al antiguo fondo Tomás García Figueras de la Biblioteca Nacional de España. 
españoles, preocupados por el posible apoyo de alguno de ellos a los rifeños. El 25 de mayo de 1922 se envió un documento generado por la Alta Comisaría donde se ponían de manifiesto los problemas generados por la existencia de dos gabinetes gubernamentales en Turquía:

[...] determinadas gestiones que una misión rifeña en Paris hizo cerca de una Delegación turca en demanda de apoyo. [...] la Delegación turca a la que se supone se habrá dirigido en París la misión rifeña es, sin duda a mi juicio [,] una Delegación kemalista que hay en aquella capital en representación del Gobierno de Angora, no reconocido y con el que por consiguiente no tiene relaciones ésta Legación [de España en París]. [...] podría interesarle que la Embajada de su S. M. en París, por medio de confidentes o de un Agente especial que estuviese en contacto con esa Delegación turca [...]. En este sentido sería a mí entender muy importante y favorable la amistad que pudiera entablar con Mustafá Kemal un agente [español] [...], cuya sola presencia cerca del Gobierno [de Ankara] de hecho lo halagaría entorpeciendo cualquiera gestión en contra de nuestros intereses ${ }^{23}$.

La preocupación española ante la ayuda de los nacionalistas turcos a los rifeños estaba vinculada, en este caso concreto, al paradero desconocido de dos submarinos de origen alemán que poseían los partidarios de Kemal Atatürk y que, bajo ningún concepto, podían acabar en manos de Abd-el-Krim. El posible papel de Alhucemas como base naval de submarinos, propios o de algún poder extranjero, fue un miedo permanente de los militares españoles. Incluso se llegaron a emitir informes en los que se daba por verdad tal posibilidad; en un telegrama cifrado en 1924 se decía: «[...] me aseguran que cabecilla rebelde dispone un submarino provisto telegrafía» ${ }^{24}$.

Otro de los elementos que justificaban el establecimiento de relaciones con los nacionalistas turcos fue el problema del liderazgo religioso en el Islam. El gobierno de Ankara había impugnado el papel que el Sultán otomano había desempeñado hasta ese momento como guía supremo de los musulmanes a través de la siguiente argumentación: « [...] el Sultán jefe supremo está imposibilitado [...] de ejercer la autoridad espiritual en la forma que realmente convenga al islamismo ya que aparece prisionero e intervenida su autoridad por los aliados»25. El descrédito al que Kemal Atatürk sometió a la figura del Sultán otomano por estar sometido a la influencia de los poderes extranjeros, fue la misma política que desarrolló Abd el Krim en Marruecos

23 Documento fechado en Tetuán a 25 de mayo de 1922, con el membrete de la Alta Comisaría de España en Marruecos (Gabinete Militar), y que contiene de informaciones procedentes de la Embajada de España en París. En Archivo General Militar de Madrid, Fondo África, Ministerio de la Guerra, Est. 2, Cuerpo 5, Tab. 4, Leg. 316, Carpeta 7.

24 En Archivo General Militar de Madrid, Fondo África, Ministerio de la Guerra, Est. 1, Cuerpo 2, Tab. 4, Leg. 4, Carpeta 2.

${ }_{25}$ Documento fechado en Tetuán a 25 de mayo de 1922, con el membrete de la Alta Comisaría de España en Marruecos (Gabinete Militar), y que contiene de informaciones procedentes de la Embajada de España en París. En Archivo General Militar de Madrid, Fondo África, Ministerio de la Guerra, Est. 2, Cuerpo 5, Tab. 4, Leg. 316, Carpeta 7. 
con respecto al Sultán alauita -en poder de los franceses - y al Jalifa, en poder de los españoles. Pero la política turca a ese respecto tenía una mayor relevancia porque el Imperio Otomano constituía el último reducto de Estado islámico y aún se reconocía en el mundo musulmán la autoridad moral del Sultán de Estambul. La desaparición de este liderazgo religioso podía tener dos consecuencias igualmente graves: la atomización de esa jefatura religiosa, que podía llegar hasta los líderes de las cabilas por ejemplo, y/o la aparición de un nuevo director de los designios islámicos bajo la protección de Ankara.

Todo lo que se ha visto hasta el momento justifica el protagonismo que los turcos tuvieron en las sospechas de los militares españoles ante un complot internacional en su contra. La espada de Damocles de la intervención de Ankara en asuntos rifeños siempre pendió, desde la perspectiva española, sobre su cabeza. Las referencias a encuentros secretos entre agentes turcos y rifeños y a supuestos pactos y alianzas estuvieron muy presentes en la geoestrategia colonial. La diplomacia secreta entre Adbel-Krim y Kemal Atatürk funcionaría a través de oficiales turcos en el Protectorado y agentes rifeños en capitales europeas donde Ankara tenía legaciones. Sirva de ejemplo la nota informativa del 18 de noviembre de 1923 que se refería a un "oficial turco" que «trae varias cartas para Abd-el-Krim de Kemal Pacha»26. Tales comunicaciones certificaban la alianza que, muchos documentos cifrados españoles, daban por hecho: «Abd-el-Krim y Mustafá Kemal están en pleno acuerdo y que el primero aspira a dominar en todo Marruecos con el título de Jalifa de Kemal»27.

Cabe preguntarse, en qué se sustentaba la supuesta ayuda turca a la causa rifeña. En este sentido, la presencia de oficiales turcos en el Protectorado español quedó plasmada en multitud de escritos confidenciales que informaban de supuestas actividades de éstos, entre las que destacaban el contrabando, el asesoramiento y la instrucción militar. En torno a estos dos últimos supuestos destacó, por su alta graduación, la presencia de un coronel turco (Ramiz Bey) que asesoraba a los rifeños en su guerra contra españoles y franceses ${ }^{28}$. Más habituales fueron los telegramas que notificaban de la presencia de oficiales turcos de baja graduación en el tráfico de armas a la República del Rif. Dichos militares ejercerían el papel doble de contrabandistas e

${ }^{26}$ En Nota informativa del 18 de noviembre de 1923 (Tánger), en Archivo General Militar de Madrid, Fondo África, Ministerio de la Guerra, No clasificado (rollo 1139).

27 Nota confidencial número 11 del 26 de agosto de 1924 de la Agencia Consular de España en Fez al general Primo de Rivera y a la Oficina de Marruecos, en Archivo General de la Administración, AGA, África, 81/10347.

28 Telegrama del 23 de marzo de 1925 del Ministro Plenipotenciario de S. M. en la Legación de Constantinopla al general Primo de Rivera y a la Oficina de Marruecos, en Archivo General de la Administración, AGA, África, 81/10348. 
instructores de los artefactos bélicos que transportaban. El sistema que empleaban para hacer llegar el estraperlo a las costas marroquíes era complejo y variado, con el fin de esquivar a la marina de guerra española. Muchas de las armas no provenían de las reservas turcas, sino que eran compradas en el mercado internacional por agentes al servicio de Ankara, especialmente de nacionalidad árabe y egipcia, y las desviaban a países musulmanes amigos para trasportarlas desde éstos a puntos costeros cercanos al Rif y, de ahí, a algún enclave bajo control de Abd-el-Krim.

El complejo entramado contrabandista tenía en el puerto de Gibraltar una de sus principales bases de operaciones. Un informe de 1921 recoge el interesante testimonio de un comerciante en relación al estraperlo de armas y pertrechos desde la plaza de soberanía británica en el Estrecho:

El Turco Jemaldine Mejdali me dice que viniendo de Tetuán a Ceuta para asuntos comerciales ha conocido rifeños que [...] viéndolo vestido a lo turco, le tomaron por un oficial turco y le dieron todos los detalles de su complot instándole a que se fuese con ellos [...] y poco después se marchó en un barco con tres europeos y cuatro indígenas, los siete oficiales de reserva franceses que me dijeron iban al campo rifeño a manejar cañones para combatir contra los españoles. [...] Después yo partí a Gibraltar con los otros rifeños que quedaban, allí para comprar municiones [...] y compraron setecientas cajas de petróleo y fusiles y cartuchos ${ }^{29}$.

La marina de guerra española estuvo los años centrales de la década de los veinte en estado de alerta por las supuestas grandes cantidades de armas transportadas por agentes turcos al Rif. En un telegrama cifrado del 5 de septiembre de 1924 de la Presidencia del Directorio Militar a la Alta Comisaría de España en Marruecos, se avisaba de la inminente llegada a las costas rifeñas de barcos a vela comandados por un capitán de ametralladoras y otros tres oficiales, sin especificar rango, de origen turco. Dichos navíos transportarían 1.700 fusiles y 160.000 cartuchos $^{30}$. El 8 de octubre del mismo año, se avisó al Alto Comisario del embarque de piezas de artillería y ametralladoras en un vapor propiedad de un turco pero sin bandera de ese país y que iría a Egipto para, posteriormente, iniciar la marcha al Rif (se desconocía si vía

29 Copia de la declaración transcrita del comerciante turco Jemaldine Mejdali, que fue enviada por el Gobernador Militar de Málaga al Alto Comisario el 27 de julio de 1921. En Archivo General Militar de Madrid, Fondo África, Ministerio de la Guerra, Est. 1, Cuerpo 2, Tab. 10, Leg. 30, Carpeta 7.

30 Telegrama clasificado que fue enviado el 5 de septiembre de 1924 desde Madrid por la Presidencia del Directorio Militar a la Alta Comisaria de España en Marruecos, Tetuán. En Archivo General Militar de Madrid, Fondo África, Ministerio de la Guerra, Est. 1, Cuerpo 2, Tab. 4, Leg. 1, Carpeta 33. 
marítima o terrestre). En el barco aludido viajarían 14 oficiales del ejército turco ${ }^{31}$. Hemos destacado estas informaciones por la importancia material de los envíos y por la presencia de oficiales turcos en los mismos pero el protagonismo de esa nacionalidad dentro del complot "panislámico" o "nacionalista” fue una constante.

Los turcos fueron los agentes del mundo musulmán más tenidos en cuenta por los servicios de información españoles, aunque, según éstos, fueron igualmente muy dispares sus intenciones y su vinculación con los "rebeldes" rifeños: en algunos de los documentos se hablaba de motivaciones religiosas -islamismo- y, en otros, se hacía referencia al carácter nacionalista del movimiento de Kemal Atatürk y se temía su imitación en el contexto magrebí. Incluso se llegó a barajar la opción de una reconstrucción del Imperio Otomano, que había de tener en el Rif su extremo más occidental. En cualquier caso, la conexión Rif-Turquía fue todo un clásico en las teorías de la inteligencia española.

\section{Conclusión}

Las informaciones que se recibían en el Protectorado español sobre las intrigas de agentes extranjeros para perjudicar la misión colonial, acabaron conformando en un amplísimo sector castrense una visión muy negativa de las intenciones de ciertos países con respecto a España. Imagen que fue nefasta en el caso de la Unión Soviética. El comunismo era el enemigo por antonomasia puesto que esa ideología rabiosamente anti-colonial era considerada la causante de la mayor parte de los males de la nación y, además, la promovedora de un complot internacional revolucionario para la subversión del orden establecido.

La misión desestabilizadora bolchevique se articuló en torno a todo tipo de estrategias y ardides: se infiltraron en la metrópoli promoviendo el antimilitarismo y el rechazo a la intervención colonial, incentivaron las huelgas y las revueltas populares, animaron a destruir el orden del ejército desde dentro, se aliaron con el "panislamismo", al que enardecieron contra las potencias metropolitanas y a quien dotaron de medios materiales de combate... Fueron, todos ellos, motivos que provocaron un profundo odio y resentimiento de muchos militares españoles con el comunismo y, por extensión, con toda ideología cercana al obrerismo, algo que quedará

${ }^{31}$ Telegrama cifrado del 8 de octubre de 1924 de la Presidencia del Directorio Militar al Alto Comisario, en Archivo General Militar de Madrid, Fondo África, Ministerio de la Guerra, Est. 1, Cuerpo 2, Tab. 4, Leg. 1, Carpeta 33. 
reflejado de manera patente - y desgraciada en grado sumo - apenas diez años más tarde. 


\section{* El autor}

Daniel Macías Fernández es doctor internacional por la Universidad de Cantabria. Es autor de El Islam y el islamismo: religión e ideología (Madrid, FINVESPOL, 2015) y Sociedad Contemporánea (Barcelona, FUNIBER, 2014). Ha coeditado La Guerra: Retórica y propaganda (Madrid, Biblioteca Nueva, 2015); David frente a Goliat: guerra y asimetría en la edad contemporánea (Madrid, IUGM, 2014); El Combatiente a lo largo de la Historia (Santander, PubliCan, 2012). Se ha de destacar que es socio-fundador de la Asociación Española de Historia Militar y, actualmente, miembro de su junta directiva.

URL: < http://www.studistorici.com/progett/autori/\#MaciasFernandez >

\section{Per citare questo articolo:}

MACÍAS FERNÁNDEZ, Daniel, «La conspiración turco-comunista: espías, contrabandistas e instructores en el Rif», Diacronie. Studi di Storia Contemporanea : La voce del silenzio: intelligence, spionaggio e conflitto nel XX secolo, 29/12/2016,

URL:< http://www.studistorici.com/2016/12/29/macias-fernandez_numero_28/ >

Diacronie Studi di Storia Contemporanea $\beta$ www.diacronie.it

Risorsa digitale indipendente a carattere storiografico. Uscita trimestrale. redazione.diacronie@hotmail.it

Comitato di redazione: Jacopo Bassi - Luca Bufarale - Antonio César Moreno Cantano - Deborah Paci - Fausto Pietrancosta - Alessandro Salvador - Matteo Tomasoni - Luca Zuccolo

Diritti: gli articoli di Diacronie. Studi di Storia Contemporanea sono pubblicati sotto licenza Creative Commons 3.0. Possono essere riprodotti e modificati a patto di indicare eventuali modifiche dei contenuti, di riconoscere la paternità dell'opera e di condividerla allo stesso modo. La citazione di estratti è comunque sempre autorizzata, nei limiti previsti dalla legge. 